University of Nebraska - Lincoln

DigitalCommons@University of Nebraska - Lincoln

Improving evapotranspiration simulations in the CERES-Maize model under limited irrigation

\author{
K.C. DeJonge \\ USDA-ARS, kendall.dejonge@ars.usda.gov
}

J.C. Ascough II

USDA-ARS

A.A. Andales

Colorado State University - Fort Collins

N.C. Hansen

Colorado State University - Fort Collins

L.A. Garcia

Colorado State University - Fort Collins

See next page for additional authors

Follow this and additional works at: https://digitalcommons.unl.edu/usdaarsfacpub

DeJonge, K.C.; Ascough, J.C. II; Andales, A.A.; Hansen, N.C.; Garcia, L.A.; and Arabi, M., "Improving evapotranspiration simulations in the CERES-Maize model under limited irrigation" (2012). Publications from USDA-ARS / UNL Faculty. 1154.

https://digitalcommons.unl.edu/usdaarsfacpub/1154

This Article is brought to you for free and open access by the U.S. Department of Agriculture: Agricultural Research Service, Lincoln, Nebraska at DigitalCommons@University of Nebraska - Lincoln. It has been accepted for inclusion in Publications from USDA-ARS / UNL Faculty by an authorized administrator of DigitalCommons@University of Nebraska - Lincoln. 


\section{Authors}

K.C. DeJonge, J.C. Ascough II, A.A. Andales, N.C. Hansen, L.A. Garcia, and M. Arabi 


\title{
Improving evapotranspiration simulations in the CERES-Maize model under limited irrigation
}

\author{
K.C. DeJonge ${ }^{\mathrm{a}, *}$, J.C. Ascough II ${ }^{\mathrm{b}}$, A.A. Andales ${ }^{\mathrm{c}}$, N.C. Hansen ${ }^{\mathrm{c}}$, L.A. Garcia ${ }^{\mathrm{d}}$, M. Arabi $^{\mathrm{d}}$ \\ a USDA-ARS, Water Management Research Unit, Fort Collins, CO 80526, USA \\ b USDA-ARS, Agricultural Systems Research Unit, Fort Collins, CO 80526, USA \\ ${ }^{c}$ Department of Soil and Crop Sciences, Colorado State University, Fort Collins, CO 80523, USA \\ d Department of Civil and Environmental Engineering, Colorado State University, Fort Collins, CO 80523, USA
}

\section{A R T I C L E I N F O}

\section{Article history:}

Received 28 March 2012

Accepted 23 August 2012

\section{Keywords:}

Crop model

Evaporation and transpiration

Deficit irrigation

Crop coefficient

Water production functions

\begin{abstract}
A B S T R A C T
Limitations on water resources for agriculture in places such as Colorado, USA, have caused farmers to consider limited irrigation as an alternative to full irrigation practices, where the crop is intentionally stressed during specific growth stages in an effort to maximize yield per unit water consumed, or evapotranspiration (ET). While crop growth models such as CERES-Maize provide the ability to evaluate numerous management scenarios without the costs associated with multiyear field experiments, recent studies have shown that CERES-Maize performs well under full irrigation but overestimates ET of corn under limited irrigation management. The primary objective of this study was to improve CERES-Maize ET simulation under limited irrigation management while maintaining accuracy of other important model output responses. Field experiments with corn were performed in northern Colorado, USA from 2006 to 2010, where four replicates each of full (ET requirement supplied by irrigation throughout the season) and limited (no irrigation before the V12 growth stage unless necessary for emergence, then full irrigation afterwards) irrigation treatments were analyzed. The local sensitivity of model input parameters affecting ET was evaluated, prompting changes to the model code with a new dynamic crop coefficient $\left(K_{C D}\right)$ as a function of the crop leaf area index. The modified CERES-Maize model more accurately represented ET under full and limited irrigation, for example reducing late-season ET potential from a plant with reduced canopy and more closely matched FAO-56 crop coefficient curves under full irrigation. Using the limited irrigation data for evaluation, the modified model showed significant decreases in model error for seasonal cumulative ET (root mean square deviation RMSD from $80.9 \mathrm{~mm}$ to $49.9 \mathrm{~mm}$ ) and water productivity (RMSD from $5.97 \mathrm{~kg} \mathrm{ha}^{-1} \mathrm{~mm}^{-1}$ to $2.86 \mathrm{~kg} \mathrm{ha}^{-1} \mathrm{~mm}^{-1}$ ) as compared to the original model. The modified model was subsequently applied to several hypothetical irrigation management strategies, indicating that reducing weekly vegetative stage water applications from $20 \mathrm{~mm}$ to $2.5 \mathrm{~mm}$ can increase simulated water productivity by over $15 \%$. While these synthetic water production functions may not be feasible in a production field with natural climate variability, the modified ET model indicates promise for limited irrigation management increasing water productivity.
\end{abstract}

Published by Elsevier B.V.

\section{Introduction}

Water availability issues, combined with population growth and the uncertainty of climate change have created significant water resource challenges (Anderson-Wilk, 2008). English et al. (2002) argued that a fundamental paradigm shift in agroecosystem irrigation management is inevitable as water supplies become more limited where farmers will manage irrigation to maximize net benefits instead of simply the biological objective of maximizing yields. Limited water resources and increasing pumping costs have recently caused farmers in Colorado, USA to consider

\footnotetext{
* Corresponding author. Tel.: +1 970492 7417; fax: +1 9704927408

E-mail address: Kendall.DeJonge@ars.usda.gov (K.C. DeJonge).
}

limited irrigation as an alternative to full irrigation practices. Obviously, yield potential is very important in regard to the economic optimization required for such management, but crop evapotranspiration (ET) also must be considered and quantified as the potential for Colorado water rights transfer depends on "consumptive use" or ET (Smith et al., 1996). Alternatively, farmers may consider either a reduction in planted or irrigated area, or schedule irrigation events so that plants do not encounter stress during sensitive growth stages. Thus, in many irrigated areas such as the Colorado Front Range, studies are increasingly exploring benefits of limited or deficit irrigation of water-intensive crops such as corn (DeJonge et al., 2011).

Water deficit stress, often referred to as simply water stress, is a physiological condition where plants have less than full turgor because the transpiration demand exceeds root water 
Table 1

Experimental management data in Northern Colorado field experiment (2006-2010). Management was applied equally to both treatments unless indicated otherwise.

\begin{tabular}{|c|c|c|c|c|c|}
\hline & 2006 & 2007 & 2008 & 2009 & 2010 \\
\hline Hybrid & Garst 8827 & Garst 8827 & Pioneer 38P & Pioneer P9512XR & $\begin{array}{l}\text { Producers Hybrids } \\
\text { 5004VT3 }\end{array}$ \\
\hline Planting date & May 10 & $\begin{array}{l}\text { May } 10^{\mathrm{a}} \\
\text { May } 8^{\mathrm{b}}\end{array}$ & April 30 & May 13 & May 4 \\
\hline Planting population (seeds $\mathrm{m}^{-2}$ ) & $\begin{array}{l}5.93^{\mathrm{a}} \\
7.91^{\mathrm{b}}\end{array}$ & $\begin{array}{l}5.93^{\mathrm{a}} \\
7.98^{\mathrm{b}}\end{array}$ & 7.91 & 7.91 & 7.91 \\
\hline $\mathrm{N}$ applications (date, $\mathrm{kg} \mathrm{ha}^{-1}$ ) & $\begin{array}{l}\text { June } 29(67)^{\mathrm{a}} \\
\text { June } 29(157)^{\mathrm{b}}\end{array}$ & $\begin{array}{l}\text { June } 27(67)^{\mathrm{a}} \\
\text { June } 27(157)^{\mathrm{b}}\end{array}$ & $\begin{array}{l}\text { April } 30(52) \\
\text { June } 23(157) \text { a } \\
\text { Jun } 23(191)^{\mathrm{b}}\end{array}$ & $\begin{array}{l}\text { May } 13(56) \\
\text { June } 29(168)\end{array}$ & $\begin{array}{l}\text { May } 10(90) \\
\text { June } 21(168)\end{array}$ \\
\hline Anthesis date & Not collected & $\begin{array}{l}\text { August } 3^{a} \\
\text { July } 27^{b}\end{array}$ & July 30 & $\begin{array}{l}\text { August } 2^{\mathrm{a}} \\
\text { August } 6^{\mathrm{b}}\end{array}$ & July 23 \\
\hline Harvest date & November 4 & November 14 & November 19 & November 13 & October 16 \\
\hline
\end{tabular}

a Limited irrigation treatment only.

b Full irrigation treatment only.

uptake, and typically limits productivity (Saseendran et al., 2008a). Limited irrigation practices incorporate water management under restricted water application, and minimize water stress during critical crop growth stages in order to maximize yields (Schneekloth et al., 2009). Numerous field studies have addressed corn (Zea mays L.) response to growth stage-timed irrigation (Barrett and Skogerboe, 1978; Doorenbos and Kassam, 1979; Gilley et al., 1980; Klocke et al., 2004, 2007; Payero et al., 2006, 2009; Igbadun et al., 2008; Farre and Faci, 2009; Ko and Piccinni, 2009; Mansouri-Far et al., 2010).

Crop simulation models, such as the CERES-Maize model found in the DSSAT v4.5 system, have been widely used to assess cropping and management strategies for corn (both rainfed and irrigated) for well over two decades (Jones and Kiniry, 1986; Ritchie et al., 1998; Jones et al., 2003; Hoogenboom et al., 2010). Several studies have utilized the model in the context of crop water stress (Nouna et al., 2000; Xie et al., 2001; Mastrorilli et al., 2003; Saseendran et al., 2008b), yet cropping system models could certainly benefit from improved mechanistic representation of transpiration, photosynthesis, carbon allocation, canopy temperature, and water use efficiency or productivity (Ahuja et al., 2006). Recently, DeJonge et al. (2011) provided a detailed statistical comparison of CERESMaize yield and ET output responses with field experimental data from 2006 to 2008 consisting of full and limited irrigation treatments in northern Colorado, USA, finding that CERES-Maize estimated yield adequately but slightly underestimated ET for full irrigation and overestimated ET for limited irrigation. These two observations contradict each other, as lower leaf area under limited irrigation should cause decreased photosynthesis and therefore decreased ET, instead of increased ET as the model predicted. This indicates that CERES-Maize simulations under stress may need improvement, especially in the form of a linkage between leaf area and ET since simulation of plant transpiration is not directly coupled with energy balance or stomatal behavior (Saseendran et al., 2008b).

In the context of crop water production functions, it is imperative that the model adequately simulate both yield and ET in terms of limited irrigation management. The overall objective of this study is to identify, evaluate, and improve CERES-Maize crop model processes that affect crop yield, ET, and LAI prediction under both non-stressed and stressed conditions. Specifically, this study explores CERES-Maize v4.0 crop simulations of full and limited irrigation treatments by: (1) evaluating local sensitivity of inputs for the maximum crop coefficient and the partitioning of potential soil evaporation and transpiration in terms of yield, cumulative ET, and maximum LAI output responses often used in model calibration; (2) creating and statistically evaluating a new function that calculates a dynamic crop coefficient for potential ET based on LAI, therefore determining ET demand as a function of vegetative growth; and (3) using the modified model with the new dynamic crop coefficient to predict water production functions (WPFs), or the relationship between yield and ET, using various forms of limited irrigation management in terms of application amount, scheduling, etc.

\section{Methods}

\subsection{Field experiment}

In a prior study, the CERES-Maize crop growth model was calibrated and validated using data from a multi-replicate field research experiment near Fort Collins, Colorado $\left(40^{\circ} 39^{\prime} 19^{\prime \prime} \mathrm{N}\right.$, $104^{\circ} 59^{\prime} 52^{\prime \prime} \mathrm{W}$ ) from 2006 to 2008 . Complete experimental details can be found in DeJonge et al. (2011), where 2007 was used for model calibration and 2006/2008 were used for validation. Two irrigation treatments of continuous corn were studied during the 2006-2010 growing seasons (2006-2008 data as documented in DeJonge et al. (2011) plus the additional 2009-2010 experiment years): full irrigation (ET requirement met by irrigation throughout the season) and limited irrigation (no irrigation before the V12 growth stage unless necessary for emergence, then full irrigation afterwards). In all years, early irrigations of less than $38 \mathrm{~mm}$ were required by all treatments to encourage germination and avoid total loss of crop. Irrigations were applied by a linear move sprinkler system, generally at a weekly interval. Irrigation amounts were determined by crop need (using a daily checkbook method and soil water content measurements), and supported by potential ET estimates from the onsite weather station. An onsite weather station (station FTC03; $40^{\circ} 39^{\prime} 09^{\prime \prime} \mathrm{N}, 105^{\circ} 00^{\prime} 00^{\prime \prime} \mathrm{W}$; elevation $1557.5 \mathrm{~m}$ ) within the Colorado Agricultural Meteorological Network (CoAgMet, http://ccc.atmos.colostate.edu/ coagmet/) continually recorded daily precipitation, solar radiation, minimum and maximum temperature, vapor pressure (which was converted to dew point temperature), and wind run. Field observations of soil water were generally made on a weekly basis using neutron attenuation in $30 \mathrm{~cm}$ intervals to a depth of $180 \mathrm{~cm}$, and were used in a water balance to determine seasonal ET. Yield samples were collected upon maturity each season. Field management and irrigation schedules for 2006-2010 are found in Tables 1 and 2, respectively. The soil at the study site is a Fort Collins Loam (fine-loamy, mixed, superactive, mesic Aridic Haplustalf), with water holding and textural properties shown in Table 3.

\subsection{CERES-Maize model overview}

CERES-Maize is a process-oriented corn growth model that requires various inputs for soil (texture, field capacity, permanent wilting point, saturation, saturated hydraulic conductivity, bulk density, soil root growth factor), daily weather (minimum and 


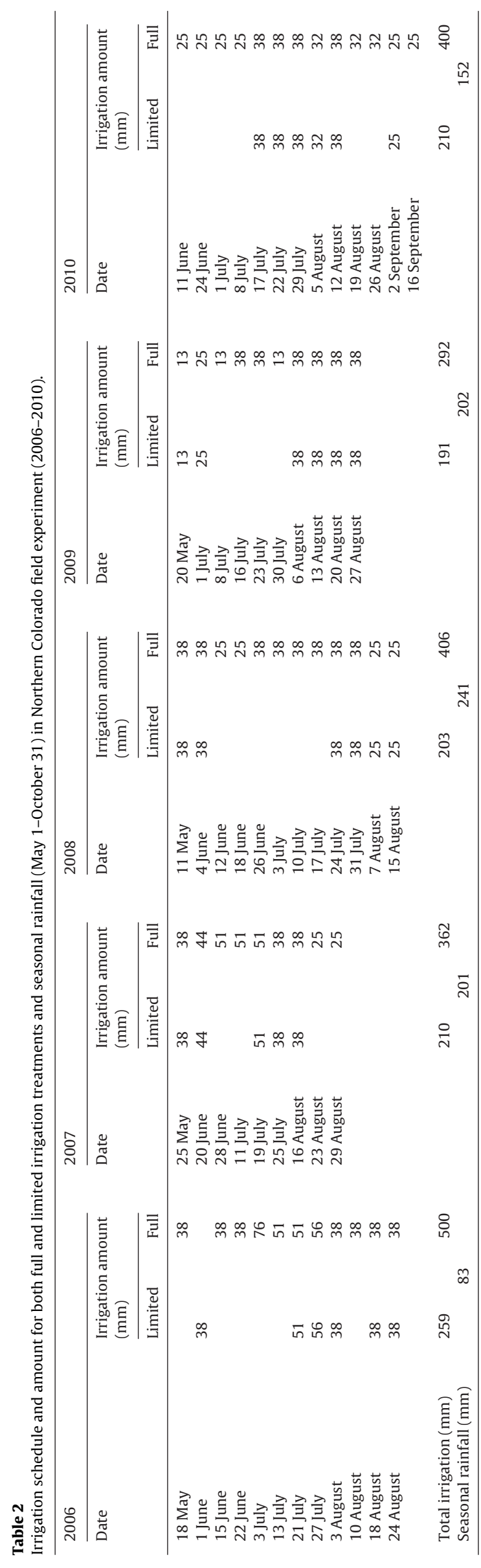

maximum temperature, solar radiation, dew point temperature, wind run, rainfall), management (planting date, $\mathrm{N}$ applications, irrigation, planting population), initial conditions (volumetric soil water content, $\mathrm{N}$ content), and phenological growth parameters specific to the hybrid or cultivar used (Jones and Kiniry, 1986). The model simulates the following: biomass accumulation based on light interception; partitioning of accumulated biomass to leaves, stems, roots, and grain; environmental stresses; soil water balance; soil $\mathrm{N}$ transformations and uptake; and crop growth and development including phenological states, biomass production, and yield. CERES-Maize crop development rates are calculated based only on temperature and photoperiod (Ritchie et al., 1998). Final LAI is calculated from the canopy leaf area balance available each day as a function of plant population, and the model does not simulate crop height (Ma et al., 2002). In terms of crop yield, number of grains per plant is a function of the potential number of kernels per plant and the average crop growth rate $\left(\right.$ g plant $\left.^{-1}\right)$ from silking to the beginning of grain filling. CERES-Maize assumes one ear of corn per plant, however if the number of kernels per plant is significantly smaller than the potential number of kernels, the model creates some barren plants. Ear growth rate $\left(\mathrm{g} \mathrm{ear}^{-1} \mathrm{day}^{-1}\right)$ is influenced by temperature but can be decreased by water or $\mathrm{N}$ stress. The effective grain filling period is based on the thermal time from silking to maturity, and during this period leaf senescence increases, whereas ears, stalks, and roots are the only active growing tissues. Daily grain growth rate is a function of temperature, grains per plant, potential kernel growth rate, and soil moisture effect on growth (Ritchie et al., 1998).

\subsection{CERES-Maize ET and water balance}

The daily soil-water balance in all DSSAT models, including CERES-Maize, uses the Ritchie (1985) and Ritchie et al. (1998) onedimensional "tipping bucket" approach, which simulates soil water flow and root water uptake for each individual user-defined soil layer (maximum of ten layers). For each layer it is required to know soil water contents (on a volumetric basis) for initial soil water content (typically found by observed values at planting), wilting point, field capacity, and field saturation. Ritchie (1985) recommends that wilting point and field capacity be determined in the field instead of from lab measurements based on disturbed samples. The root weighting factor also is required for each layer, where a maximum value of 1 indicates a soil most hospitable to root growth and a minimum value of 0 indicates the soil is inhospitable to root growth. Low values for the root weighting factor can be used to simulate restricted root growth in layers with poor physical or chemical properties. Key soil properties for the Fort Collins limited irrigation experimental site are given in Table 3; however, all values used in this study for initial soil water, wilting point, field capacity, saturation, and root weighting factor can be found in DeJonge et al. (2011). Infiltration is assumed to be rainfall plus irrigation minus runoff, calculated by the curve number method (SCS, 1972). Soil water redistribution within the soil is described in more detail in Ritchie et al. (1998), and is a function of the water contents in neighboring layers and the distance between layers. Additional information regarding simulation of water balance and water stress components can be found both in Saseendran et al. (2008a) and ICASA (2008).

For CERES-Maize as implemented in DSSAT v4.5, the overall logic of ET and water stress calculation is shown in Fig. 1. Reference evapotranspiration ( $\left.\mathrm{ET}_{0}\right)$ was calculated in earlier versions of the model using the Priestley-Taylor method (Priestley and Taylor, 1972) whose inputs are solar radiation and minimum and maximum temperature. Current versions of the DSSAT CSM can also use 
Table 3

Soil properties at the Fort Collins limited irrigation experimental site.

\begin{tabular}{|c|c|c|c|c|}
\hline Depth from surface (mm) & Wilting point $\left(\mathrm{mm}^{3} \mathrm{~mm}^{-3}\right)$ & Field capacity $\left(\mathrm{mm}^{3} \mathrm{~mm}^{-3}\right)$ & Sand (\%) & Clay (\%) \\
\hline $0-150$ & 0.100 & 0.320 & 37.4 & 31.0 \\
\hline $150-300$ & 0.150 & 0.280 & 37.4 & 31.0 \\
\hline $300-450$ & 0.150 & 0.325 & 36.0 & 31.0 \\
\hline $450-600$ & 0.179 & 0.262 & 34.2 & 31.2 \\
\hline $600-900$ & 0.169 & 0.400 & 40.3 & 31.7 \\
\hline 900-1200 & 0.160 & 0.420 & 48.6 & 27.1 \\
\hline $1200-1500$ & 0.180 & 0.400 & 46.4 & 29.2 \\
\hline $1500-1780$ & 0.180 & 0.420 & 44.4 & 30.4 \\
\hline
\end{tabular}

the FAO-56 Penman-Monteith method which requires additional wind and humidity data (Allen et al., 1998):

$\mathrm{ET}_{o}=\frac{0.408 \Delta\left(R_{n}-G\right)+\gamma\left(\frac{900}{T+273}\right) U_{2}\left(e_{s}-e_{a}\right)}{\Delta+\gamma\left(1+0.34 U_{2}\right)}$

where $\mathrm{ET}_{o}$ is the hypothetical reference crop ET rate $\left(\mathrm{mm} \mathrm{d}^{-1}\right), R_{n}$ the net radiation flux density at the surface $\left(\mathrm{MJ} \mathrm{m}^{-2} \mathrm{~d}^{-1}\right), \mathrm{G}$ the sensible heat flux density from the surface to the soil $\left(\mathrm{MJ} \mathrm{m}^{-2} \mathrm{~d}^{-1}\right), \gamma$ the psychrometric constant $\left(\mathrm{kPa}{ }^{\circ} \mathrm{C}^{-1}\right), T$ is mean air temperature $\left({ }^{\circ} \mathrm{C}\right), U_{2}$ is wind speed $\left(\mathrm{m} \mathrm{s}^{-1}\right)$ at $2 \mathrm{~m}$ above the ground (relative humidity and dew point are also assumed to be measured at this height), $e_{s}$ is mean saturated vapor pressure ( $\left.\mathrm{kPa}\right)$ computed as the mean vapor pressure as calculated at the daily minimum and maximum temperature, $e_{a}$ is the actual vapor pressure of the air $(\mathrm{kPa})$, and $\Delta$ is the slope of the saturation vapor pressure versus temperature curve $\left(\mathrm{kPa}^{\circ} \mathrm{C}^{-1}\right)$.
Potential crop ET (E0) is calculated from:

$E 0=K_{C S} \times \mathrm{ET}_{0}$

where $K_{C S}$ is the static CERES-Maize crop coefficient. In the context of this study, it is important to understand that $K_{C S}$ is not necessarily the same as a crop coefficient in the traditional sense $\left(K_{c}\right)$ as described by Allen et al. (1998). While it is true that the crop coefficient $K_{c}$ is multiplied by a reference ET, the resulting value denotes ET demand and not necessarily actual ET. CERES-Maize model code employs the following formula for calculation of $K_{C S}$ :

$K_{C S}=1.0+\left(K_{C \max }-1.0\right) \times \frac{\mathrm{LAI}}{6.0}$

where LAI is leaf area index and $K_{c \max }$ is defined as the maximum $K_{C S}$ at LAI $=6.0$ (Sau et al., 2004). This formula ensures that $K_{C S}$ varies daily between 1.0 and $K_{c \max }$. Values of $K_{c \max }$ less than 1 should not be used, as this would actually decrease the ET based on increased

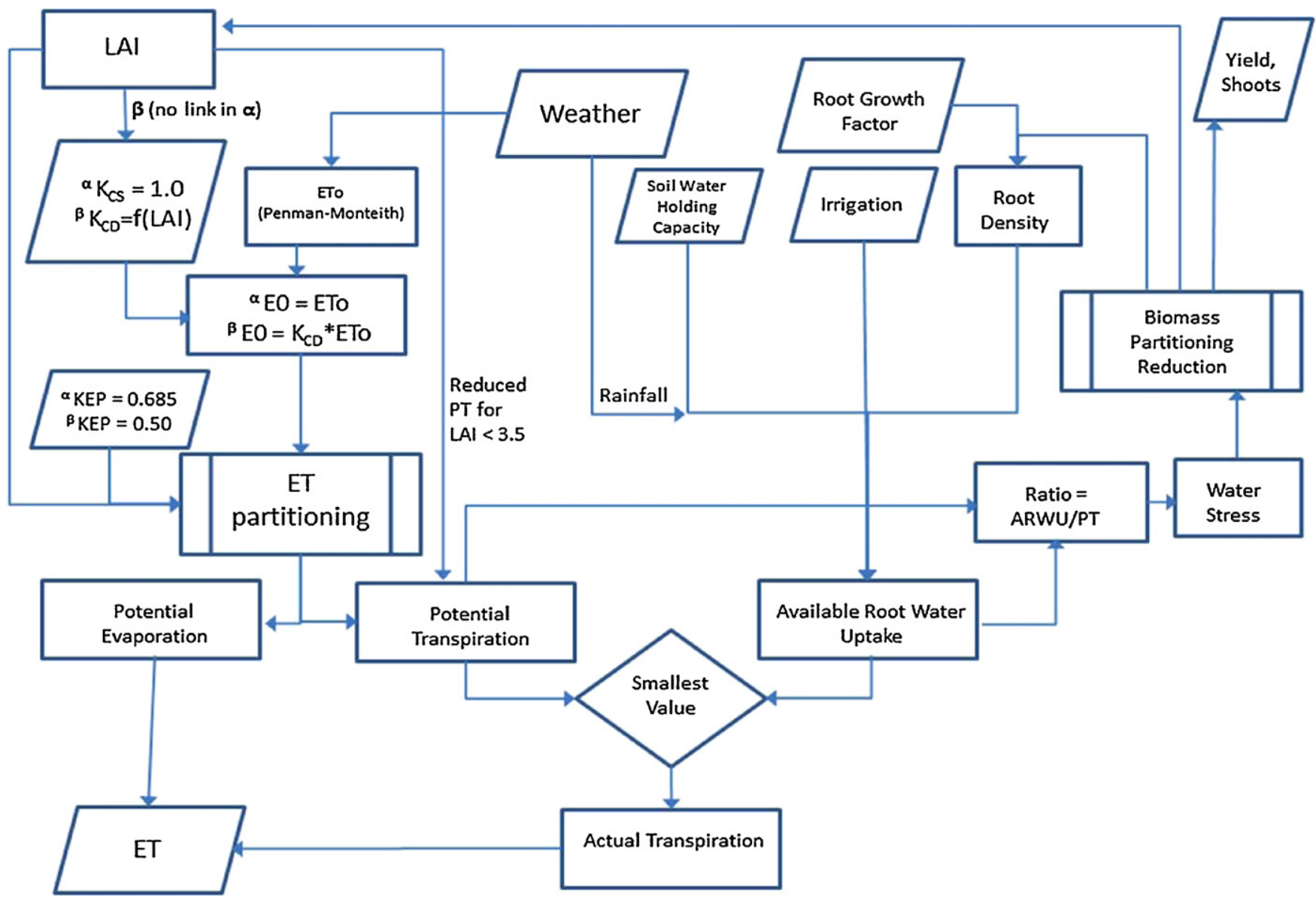

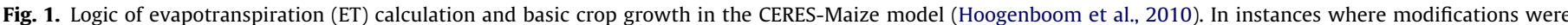

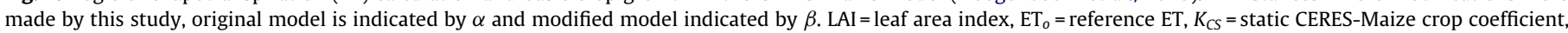
$K_{C D}=$ dynamic crop coefficient, $E 0=$ potential model ET, $\mathrm{KEP}=$ partitioning coefficient for evaporation and transpiration 


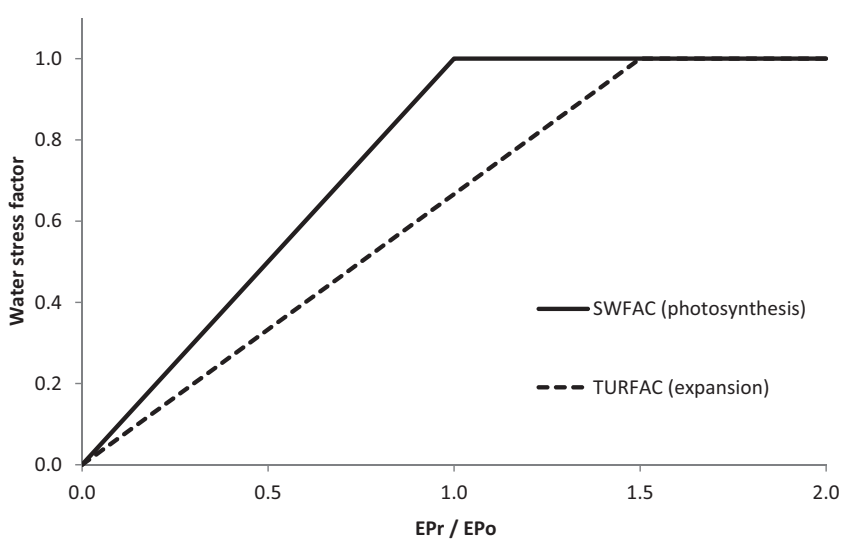

Fig. 2. Water stress factors SWFAC (photosynthesis) and TURFAC (expansion) used in DSSAT models as a function of the ratio of potential water uptake $\left(\mathrm{EP}_{r}\right)$ to potential transpiration $\left(\mathrm{EP}_{0}\right.$ ) (Ritchie et al., 1998 via Saseendran et al., 2008b). Values of 1 indicate that no stress is imposed on photosynthesis or expansion processes; values between 0 and 1 will impose stresses on the crop, with lower values indicating more stress.

LAI. The current version of CERES-Maize sets the value of $K_{c \max }$ equal to 1 , ensuring that $K_{C S}$ remains at 1.0 for the entire simulation and is thus static. Allen et al. (1998) noted that closely spaced plants with tall canopy heights may have mid-season ET greater than the reference ET, and suggested a $K_{c}$ of up to 1.2 for a non-stressed maize crop. This option has been evaluated in previous studies with mixed results. For example, López-Cedrón et al. (2008) used the FAO-56 option with $K_{c \max }$ (maximum $K_{C S}$ ) of 1.0 and 1.1 (in addition to the Priestley-Taylor method) to simulate rainfed and irrigated maize biomass and yield, finding that $K_{c \max }$ greater than 1.0 proved to be too stressful on rainfed biomass and yield.

$E 0$ is partitioned into potential plant transpiration $\left(\mathrm{EP}_{0}\right)$ and potential soil evaporation $\left(\mathrm{ES}_{0}\right)$, where

$\mathrm{EP}_{o}=E 0 \times(1-\exp (-\mathrm{KEP} \times \mathrm{LAI}))$

$\mathrm{ES}_{0}=E 0-\mathrm{EP}_{0}$

where KEP (default value of 0.685 ) is defined as an energy extinction coefficient of the canopy for total solar irradiance used for partitioning $\mathrm{EO}$ to $\mathrm{EP}_{o}$ and $\mathrm{ES}_{0}$.

Soil-limited root water uptake $\left(E_{r}\right)$ is calculated based on the effective root zone of the crop and the available water within that root zone (Ritchie, 1998). The actual plant water uptake (EP) is found as the smaller of $\mathrm{EP}_{r}$ and $\mathrm{EP}_{0}$. In other words, if the potential plant evaporation (transpiration) can be supplied by the soil water, then this demand is fully met. It is important to remember that in the current version of CERES-Maize, $\mathrm{EP}_{o}$ is based on a non-stressed full canopy crop, even when the crop itself may be in the vegetative growth stage with less actual ET demand. Cases where ET demand may not be met include the beginning growth stages (where the root water uptake will be minimal) and also the prolonged water shortage. Two stress factors are calculated in CERES-Maize based on the ratio of $\mathrm{EP}_{r}$ to $\mathrm{EP}_{o}$. Under well-watered conditions, potential root water uptake is greater than potential transpiration and this ratio is greater than one. As soil dries because of root water uptake, $\mathrm{EP}_{r}$ is reduced, and eventually a threshold is reached where the turgor stress factor (TURFAC, Fig. 2) is triggered, limiting expansive growth which is considered more sensitive to drought stress than other growth and development processes (Saseendran et al., 2008a). In the current version of the model, this is calculated as:

TURFAC $=\frac{\mathrm{EP}_{r}}{\mathrm{RWUEP}_{1} \times \mathrm{EP}_{o}}$

where RWUEP1 is a species-specific parameter that is currently set to 1.5 for all DSSAT crops. When potential transpiration demand exceeds the potential root water uptake, a second stress factor affecting photosynthesis (SWFAC, Fig. 2) is activated and is calculated as:

$\mathrm{SWFAC}=\frac{\mathrm{EP}_{r}}{\mathrm{EP}_{o}}$

Both stress factors are bounded by values of 0 and 1 . Values of 1 indicate that no stress is imposed on photosynthesis or expansion processes; values between 0 and 1 will impose stresses on the crop, with lower values indicating more stress.

\subsection{Local sensitivity of $K_{\text {cmax }}$ and KEP}

The two main model parameters and processes initially explored in this study are the maximum $K_{c}$ for FAO-56 Penman-Monteith potential ET (E0) and the KEP value partitioning $\mathrm{EP}_{o}$ and $\mathrm{EP}_{r}$ based on LAI. In an earlier study, a global sensitivity analysis was performed on CERES-Maize using the same northern Colorado, USA datasets (i.e., 2006-2010), and verified that the limited irrigation treatment was very sensitive to inputs affecting the soil's available water capacity, whereas the full irrigation treatment showed minimal sensitivity (DeJonge et al., 2012). In this manuscript, a local sensitivity analysis (SA) of $K_{c \max }$ and KEP was performed by manually changing the baseline (default) parameter values through input files and code manipulation. Five years of management data (2006-2010) were used with the two irrigation treatments (separated in the SA) to simulate CERES-Maize output variability. Model output responses evaluated included yield at maturity $\left(\mathrm{kg} \mathrm{ha}^{-1}\right)$, maximum seasonal LAI, and cumulative ET $(\mathrm{mm})$. Mean and standard deviation of the output responses for each treatment were calculated, as well as the overall change (\%) from the mean values using the baseline run.

As suggested by Allen et al. (1998), the crop coefficient $\left(K_{c}\right)$ can be as high as 1.2 for midseason corn. The DSSAT code was modified to remove the hard-coded $K_{C S}$ value (currently set to 1.0) and thus allow a maximum $K_{C S}$ value (as set by $K_{c \max }$, Eq. (3)) to be initialized in the maize species input file. $K_{c \max }$ values of $1.1,1.2$, and 1.3 were compared with the baseline value $K_{c}$ of 1.0 . While $K_{c \max }$ of 1.3 may give higher than expected $K_{C S}$ values, maximum observed LAI in Colorado, USA is typically not much higher than 5.0 (DeJonge et al., 2011), which using Eq. (3) would give a $K_{c}$ of 1.25 .

Values of KEP were changed to evaluate the effects of varying partitioning to potential transpiration and potential soil evaporation based on LAI (Eq. (4)). Different KEP values have been investigated in previous studies, for example, Sau et al. (2004) used a KEP value of 0.85 with DSSAT v3.5 and López-Cedrón et al. (2008) used a value of 0.685 with DSSAT v4.0. Both authors recommended lowering the KEP value to 0.5 for better simulation of biomass and yield and López-Cedrón et al. (2008) evaluated a KEP of 0.5 in rainfed maize. However, no analysis of the direct effect of changing these values on ET or LAI was made in either study. For the purposes of this study, KEP was evaluated using the CERES-Maize default value $(0.685)$ and three other values $(0.605,0.524$, and 0.444$)$.

\subsection{Dynamic $K_{C D}$ calculation}

In order to potentially improve the simulation of ET in CERESMaize, it is desirable to replace Eq. (3) with a new estimation of $K_{C S}$ that more reasonably estimates the ET demand as a function of LAI. A few past studies (e.g., Al-Kaisi et al., 1989; Kang et al., 2003; Duchemin et al., 2006) show a direct relationship between the traditional crop coefficient $\left(K_{c}\right)$ and LAI (Fig. 3). All of the studies used lysimeters to determine ET and all were for corn with the exception of Duchemin et al. (2006) which was for wheat, and is shown for comparison purposes. Although this study focuses on corn, there are limited examples in the literature that directly compare $K_{c}$ and 


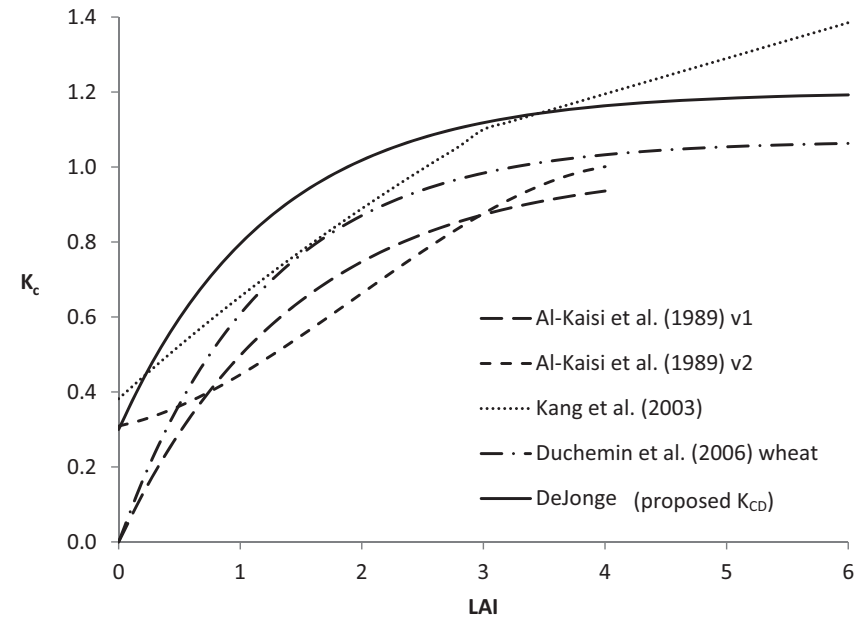

Fig. 3. Crop coefficient $\left(K_{c}\right)$ versus leaf area index (LAI) relationships found in literature, and newly proposed dynamic crop coefficient function $\left(K_{C D}\right)$ for this study: $K_{C D}=0.3+0.9 \times(1-\exp (-0.8 \times \mathrm{LAI}))$.

LAI, and wheat has similar crop coefficient characteristics to corn (Allen et al., 1998). The $K_{c}$ versus LAI relationships generally had $R^{2}$ between 0.72 and 0.86 , and the first leg of the Kang et al. (2003) relationship (i.e., up to an LAI of 3 ) had an $R^{2}$ of 0.95 . The graphs in Fig. 3 all share commonalities, for example the graphs typically start with $K_{c}$ between 0 and 0.4 for LAI $=0$, and increase in a linear or exponential limit fashion until approximately an LAI of 3, where $K_{c}$ is between 0.8 and 1.1. At this point the relationships level off with small increases in $K_{c}$ for any increase in LAI. Several of the studies showed that ET demand does not significantly increase as LAI increases above 3 since this LAI level is near the maximum intercepted net radiation. It is worth noting that the curves predicted by Al-Kaisi et al. (1989) and Duchemin et al. (2006) are debatable at low values of LAI (e.g., at LAI $=0$ there is no canopy yet there would still be soil surface evaporation, thus $K_{c}>0$ ).

For the purposes of improving the CERES-Maize crop growth model, it is desirable to link the factors governing interception of solar radiation (i.e., LAI) with those governing ET demand (i.e., $K_{C S}$ ) to provide for a more mechanistic representation of the ET process. Based on production functions used in previous studies (Fig. 3), the following dynamic exponential decay function $K_{C D}$ is proposed and evaluated to replace $K_{C S}$ as determined in Eq. (3):

$K_{C D}=K_{c \min }+\left(K_{c \max }-K_{c \min }\right)\left(1-\exp \left(-S K_{c} \times \mathrm{LAI}\right)\right)$

where $K_{c \min }$ is the minimum crop coefficient or $K_{C D}$ at LAI $=0, K_{c \max }$ is the maximum crop coefficient at high LAI, and $S K_{c}$ is a shaping parameter that determines the shape of the $K_{C D}$ versus LAI curve. The three unknown terms (other than LAI) in this function were added to the model code as parameters in a new input file. Based on several examples of $K_{c \min }$ and $K_{c \max }$ for various crops in FAO-56 (Allen et al., 1998), suggested values for these parameters for corn are $0<K_{c \min } \leq 0.4$ and $0.9 \leq K_{c \max } \leq 1.2$. Because $S K_{c}$ is a new parameter introduced in this manuscript, the authors suggest $0.5 \leq S K_{c} \leq 1.0$ as a typical range to match the general shape and scale of other experiments as shown in Fig. 3.

Both irrigation treatments were evaluated using 2006-2010 data after replacing Eq. (3) with Eq. (8). Values for $K_{c m i n}$ and $K_{c \max }$ were set at 0.3 and 1.2 , respectively, based on typical values expected for corn (Allen et al., 1998). This ensured an early season $K_{C D}$ near 0.3 before significant canopy growth, as well as $K_{C D}$ well above 1 with higher LAI. Additionally, $S K_{c}$ was set to 0.8 to resemble trends found in previous studies (Fig. 3) and KEP was set to 0.5 to follow recommendations by Sau et al. (2004). Model changes are indicated by $\beta$ in Fig. 1.

\subsection{Synthetic water production functions}

To evaluate the irrigation scenarios described above, the new $K_{C D}$ function was analyzed using the irrigation treatments from the northern Colorado, USA field experiment (full and limited irrigation), along with three other theoretical treatments (Table 4). Five years of historical weather data were used (2001-2005), using the onsite CoAgMet weather database for weather inputs (FTC03, any missing data were replaced by the nearby FTC01 Fort Collins, Colorado, USA station). All scenarios were run using field observed 2006-2010 input data, except that the theoretical irrigation schedules and amounts were modifications of the observed irrigation data. In the new irrigation treatments irrigation timing was based on the full and limited irrigation treatments in that irrigation occurred only on the same dates as for the observed treatments; however, the irrigation quantities varied toward a specific objective. In order to further evaluate the effectiveness of the limited irrigation management treatments as applied in these studies, and to test CERES-Maize using climate scenarios outside of those used in the model parameterization, an additional comparison was made using synthetic limited irrigation experiments created with varying levels of water stress during the vegetative growth stage. All precipitation data were deleted and replaced with a weekly artificial water application in an effort to create a synthetic water production function. During the vegetative growth stage, effects of five application rates $\left(2.5,5,7.5,10\right.$, and $\left.20 \mathrm{~mm}_{\text {week }}{ }^{-1}\right)$ were simulated. During the reproductive and maturity stages, these weekly water applications were set at $50 \mathrm{~mm}$ to ensure a full water profile. In order to ensure that the differences in outputs only occur as a result of treatment or weather variability, all other initial conditions and management inputs were taken from the original simulations of the 2008 full irrigation treatment, including planting day of year, nitrogen applications, initial water conditions, etc.

\subsection{Statistical evaluation}

CERES-Maize simulations for yield, cumulative ET, and water productivity (WP, yield divided by cumulative ET) were performed using both the original (static $K_{C S}$ value) and modified (dynamic $K_{C D}$ function) models. Model output responses were compared with experimentally observed values using the root mean square deviation (RMSD), normalized objective function (NOF), and relative error (RE) statistical evaluation criteria:

RMSD $=\sqrt{\frac{\sum_{i=1}^{n}\left(O_{i}-P_{i}\right)^{2}}{n}}$

$\mathrm{NOF}=\frac{\mathrm{RMSD}}{\bar{O}}$

$\mathrm{RE}=\frac{(\bar{P}-\bar{O})}{\bar{O}} \times 100$

where $O_{i}$ is the observed value, $P_{i}$ is the CERES-Maize predicted value, $n$ is the total number of observations, $\bar{P}$ is the mean of all predicted values, and $\bar{O}$ is the mean of all observed values. Smaller values of RMSD among the same data type indicate better performance of the model. The NOF should be interpreted as a relative value to compare model performance of simulating different data sets. RMSD or $\mathrm{NOF}=0$ indicate perfect fit between experimental data and simulated results; $\mathrm{NOF}<1$ may be interpreted as a simulation error of less than one standard deviation around the experimental mean. RE is a measure of the average tendency of the simulated values to be larger or smaller than the observed values. The optimal RE value is 0.0 ; a positive value indicates a model bias toward overestimation, whereas a negative value indicates a model bias toward underestimation. 
Table 4

Observed and hypothetical irrigation treatments explored with the modified model.

\begin{tabular}{|c|c|c|}
\hline Treatment & Description & Goal \\
\hline Full (observed) & $\begin{array}{l}\text { Irrigation applied to meet ET demand throughout the } \\
\text { growing season }\end{array}$ & $\begin{array}{l}\text { Achieve maximum yield, zero stress throughout growing } \\
\text { season }\end{array}$ \\
\hline Limited (observed) & $\begin{array}{l}\text { During vegetative stage, irrigations only applied to } \\
\text { establish stand. Full irrigation during reproductive stage }\end{array}$ & $\begin{array}{l}\text { Intentionally stress crop during vegetative stage but } \\
\text { minimize stress after reproductive stage }\end{array}$ \\
\hline $50 \%$ full (hypothetical) & $\begin{array}{l}\text { Irrigation events on same days as full irrigation, but } 50 \% \text { of } \\
\text { full }\end{array}$ & $\begin{array}{l}\text { Reduced irrigation amount with no change in irrigation } \\
\text { timing }\end{array}$ \\
\hline Full anthesis only (hypothetical) & $\begin{array}{l}\text { Same as } 50 \% \text { full treatment, but full irrigation amounts are } \\
\text { within a week of anthesis date }\end{array}$ & $\begin{array}{l}\text { Reduced irrigation amount with no stress during sensitive } \\
\text { reproductive stage }\end{array}$ \\
\hline Stress anthesis only (hypothetical) & $\begin{array}{l}\text { Same as full irrigation treatment, but zero irrigation is } \\
\text { applied within a week of anthesis date }\end{array}$ & $\begin{array}{l}\text { Maximum stress during sensitive reproductive stage with } \\
\text { no irrigation reduction otherwise }\end{array}$ \\
\hline
\end{tabular}

\section{Results and discussion}

\subsection{Linear sensitivity of $K_{\text {cmax }}$ and $K E P$}

As expected, increasing $K_{c \max }$ (Eq. (3)) increased cumulative ET for the full irrigation treatment (Fig. 4). Cumulative ET was increased $4.6 \%$ by changing $K_{c \max }$ to 1.1 and increased $8.0 \%$ by changing $K_{c \max }$ to 1.2 . Increasing $K_{c \max }$ to 1.3 produced a smaller incremental change in cumulative ET (10.1\% higher than baseline). Because ET increased for this treatment, the water in the soil profile was less than in the baseline treatment, so a small amount of water stress was introduced that slightly decreased yield (e.g., 1.9\% decrease in yield with $K_{c \max }$ of 1.2 ) but had an even smaller effect on LAI (only a $0.8 \%$ reduction with $K_{\text {cmax }}$ of 1.3 ). DeJonge et al. (2011) showed that cumulative ET under full irrigation was generally underpredicted, with a relative error of $-7.2 \%$ for the three years (2006-2008) evaluated. Allen et al. (1998) noted that a maximum $K_{c}\left(K_{c \max }\right)$ value of 1.2 for unstressed, full canopy corn is typical; therefore, it is conceivable that this value would improve simulations of ET for fully irrigated corn.

As the limited irrigation treatment was not expected to reach full ET throughout the season, changes in $K_{c \max }$ did not have a significant impact on ET, with only a $0.7 \%$ increase in cumulative ET for $K_{c \max }$ of 1.3 (Fig. 4). Root water uptake and subsequent transpiration is limited by the smallest of ET demand and available root water (Fig. 1), which in the limited irrigation treatment is often
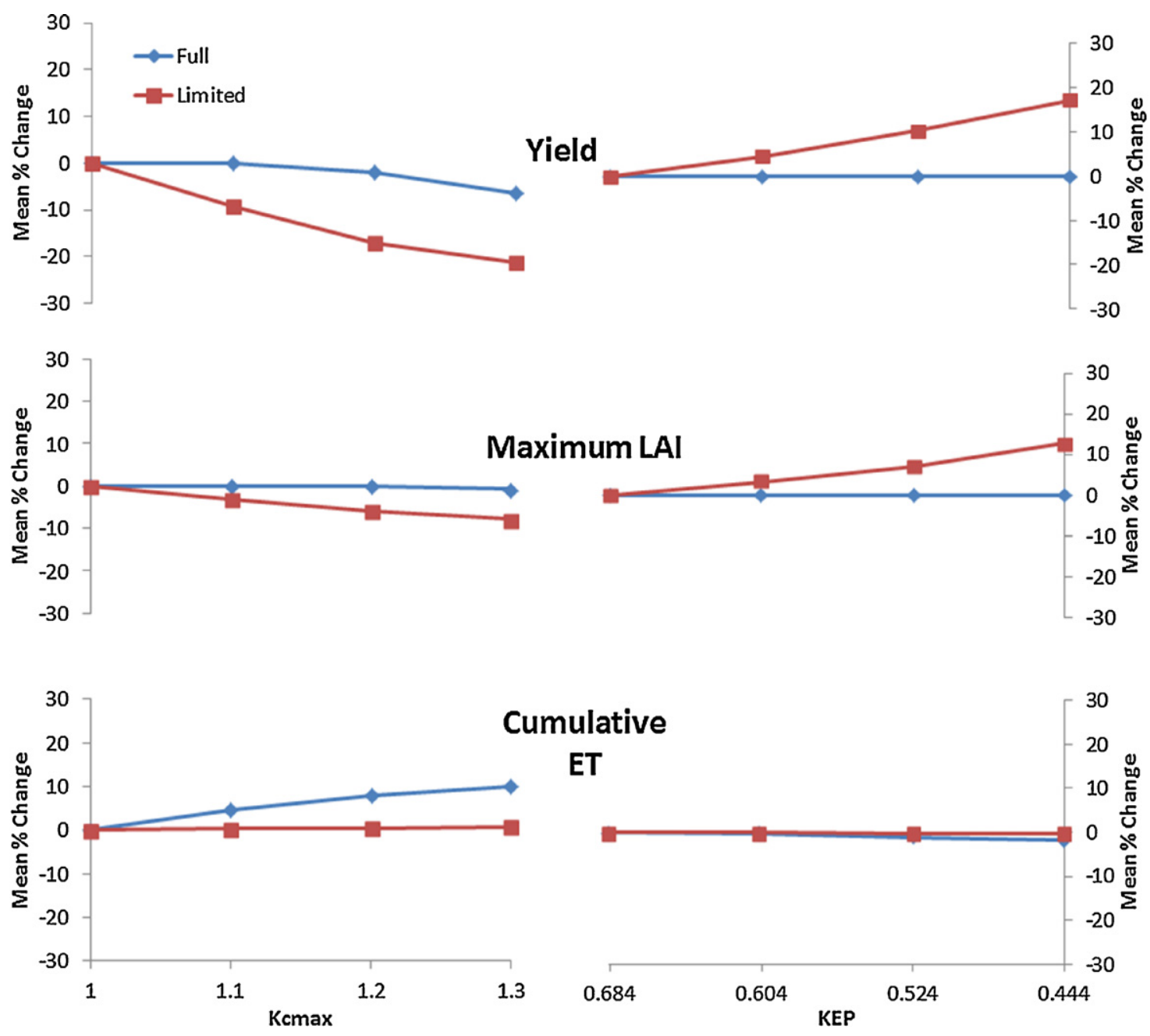

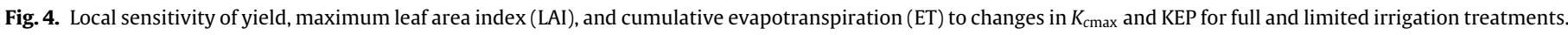
Vertical axis indicates change in output $(\%)$ from baseline $\left(K_{c \max }=1.0, \mathrm{KEP}=0.685\right)$ averaged over the five years simulated. 
the latter, regardless if the ET demand is increased as in this sensitivity analysis. However, due to the processes used to partition ET and calculate water stress, increases in $K_{c \max }$ introduced significant decreases in both yield and LAI. For example, with $K_{c \max }$ of 1.2 , yield decreased $17.2 \%$ and LAI decreased $5.8 \%$. By allowing for a higher $K_{c}$, Eq. (2) calculates a higher E0 (ET demand or potential ET). When E0 is partitioned based on Eqs. (4) and (5), this in turn produces a higher potential transpiration $\left(\mathrm{EP}_{o}\right)$. Although the overall ET rate changes little, more of ET is partitioned into crop water needs so Eqs. (6) and (7) will introduce more stress into the model, thus decreasing yield and leaf expansion. By definition, Eq. (3) limits the $K_{c}$ to values greater than 1, which in turn simulates excessive demand for a crop with less than full canopy. Eq. (8) with the dynamic $K_{C D}$ is an attempt to remedy this issue.

Values of KEP, the extinction coefficient for partitioning $E 0$ into $\mathrm{EP}_{o}$ and $\mathrm{EP}_{r}$, were varied from the baseline run of 0.685 to lower values of 0.605, 0.524, and 0.444. Both Sau et al. (2004) and LópezCedrón et al. (2008) recommend lowering KEP to around 0.5. Effects on full irrigation were minimal (Fig. 4) as expected. Since full irrigation management met the ET demand of the crop, no stress was invoked resulting in no change from baseline for yield or maximum LAI. Because shifting KEP downward changes the partitioning, a smaller amount of transpiration is apportioned to ET. However, because full irrigation has such high LAI, the differences between KEP values were minimal (e.g., a 1.9\% decrease by changing KEP from 0.685 to 0.444 ).

There was minimal response in ET $(<0.5 \%)$ to changes in KEP for the limited irrigation treatment (Fig. 4). On the other hand, there were substantial increases in yield and LAI due to decreases in KEP. As KEP is reduced (Eqs. (4) and (5)), partitioning of E0 results in lower potential transpiration $\left(\mathrm{EP}_{o}\right)$. Because this demand is more easily met, the ratio of $\mathrm{EP}_{r} / \mathrm{EP}_{o}$ will be higher and water stress functions (Eqs. (6) and (7)) will be less severe, resulting in less yield and LAI reduction. For example, changing KEP from 0.685 to 0.524 resulted in a $10.2 \%$ increase in yield and a $6.9 \%$ increase in maximum LAI.

\subsection{Dynamic $K_{C D}$ as a function of $L A I$}

The dynamic $K_{C D}$ was evaluated by using values of $K_{c \min }=0.3$, $K_{c \max }=1.2$, and $S K_{c}=0.8$, as well as changing KEP from 0.685 to 0.5 (Eqs. (4) and (5)). Full irrigation treatment data from 2008 is used in Fig. 5 to show the functionality of the new equation. The previous version of CERES-Maize has the $K_{C S}$ value hard-coded at 1.0 for the entire growing season; even by changing $K_{c \max }$ then $K_{C S}$ would still be greater than 1.0 at all times (Eq. (3)). Eq. (8) allow for a dynamic $K_{c}\left(K_{C D}\right)$ as a function of leaf canopy. Beginning at planting, the $K_{C D}$ for both irrigation treatments was near $K_{c \text { min }}$ (or 0.3) for several weeks (Fig. 5). A typical $K_{c}$ curve from FAO-56 (Allen et al., 1998) is shown for comparison purposes (dashed line). It is encouraging to see that the modified $K_{C D}$ curve for the non-stressed full irrigation treatment follows the FAO-56 $K_{c}$ curve extremely closely through most of the growing season. In the full irrigation treatment, the crop is irrigated to meet ET demand, which, as can be seen in Fig. 5, meets non-stressed values proposed by FAO-56. At the end of the season, the $K_{C D}$ curve does not drop as much as the FAO-56 curve, indicating that crop senescence may be underestimated by the model; however, the late season evaporative demand (roughly September and later) is less than the mid-season demand, so the difference in these curves would have a small effect on cumulative seasonal ET values. For comparison purposes, $K_{C D}$ is also shown for the limited irrigation treatment, indicating the lower ET demand computed as a result of smaller LAI values.

In the context of this model and Eq. (8), $K_{C D}$ will be mathematically limited to low values during the early season and under water stress (i.e., small or reduced canopy). This relationship

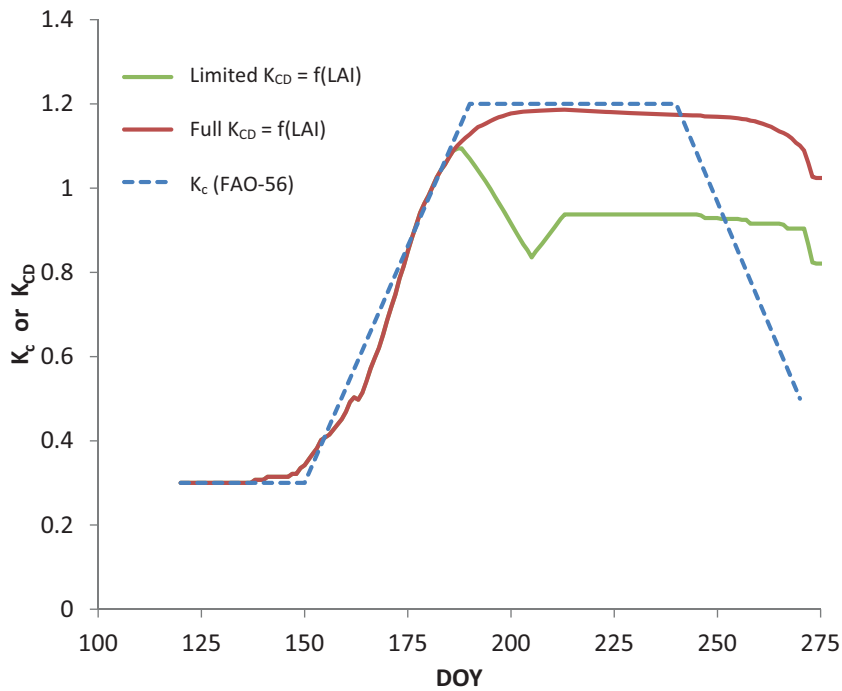

Fig. 5. Crop coefficient curve $K_{C D}$ for potential evapotranspiration (ET) in full and limited irrigation treatments (2008) as a function of leaf area index (LAI), found by Eq. (8) using $K_{c \min }=0.3, K_{c \max }=1.2$, and $S K_{c}=0.8$. For comparison purposes, a crop coefficient curve from FAO-56 is also shown (Allen et al., 1998).

essentially assumes that the soil surface is not wet and does not directly account for differences in soil evaporation when the soil is irrigated or receives rainfall, where $K_{c}$ as defined by Allen et al. (1998) would in that circumstance be greater than indicated by the dashed line in Fig. 5. However, in such cases where irrigation or rainfall is added to the water balance, CERES-Maize model ET demand will be met more easily, minimizing water stress and LAI reduction, thus calculating more ET over the course of the season as had been without the rainfall.

While one purpose of the dynamic $K_{C D}$ variable was to compute more accurate cumulative ET over the course of a season, it was also capable of determining more logical amounts of daily ET during certain growth stages. The 2008 dataset was used to show the daily ET simulation ratio, or the ratio of simulated ET under limited irrigation to simulated ET under full irrigation (Fig. 6). In both the original and modified CERES-Maize models, the ET ratio was near 1 toward the beginning of the season because the only difference between irrigation treatments at this point is the initial soil water which was quite similar. The beginning of the differences in irrigation treatments is more apparent when the ET simulation ratio becomes less than 1 (i.e., when the limited irrigation treatment is given less irrigation water). In both treatments, this ratio is reduced further, to around 0.2 as the water deficit under limited irrigation increases. Up until this point, the original CERES-Maize model behaves in a sensible manner. However, near late July (the beginning of the reproductive growth) both treatments received large amounts of water to meet ET demand. In the original model, the ET demand was generally the same in both irrigation treatments because $K_{c}$ was always 1.0 , so the ET simulation ratio was near 1 during this time of high watering. However, it is logical that a crop with reduced LAI (limited irrigation) would have less ET than a crop with greater LAI (full irrigation). With the dynamic $K_{C D}$ improvement, the modified model simulates the ratio of limited irrigation ET to full irrigation ET at a maximum of (and often below) about 0.85 during the reproductive growth stage. This example shows how overall ET simulation in CERES-Maize under water stress is different using the dynamic $K_{C D}$ function, especially in the reproductive growth stage.

The original and modified CERES-Maize models were run for all years (2006-2010) with both full and limited irrigation treatments. Simulated yield, cumulative ET, and WP for the modified model 


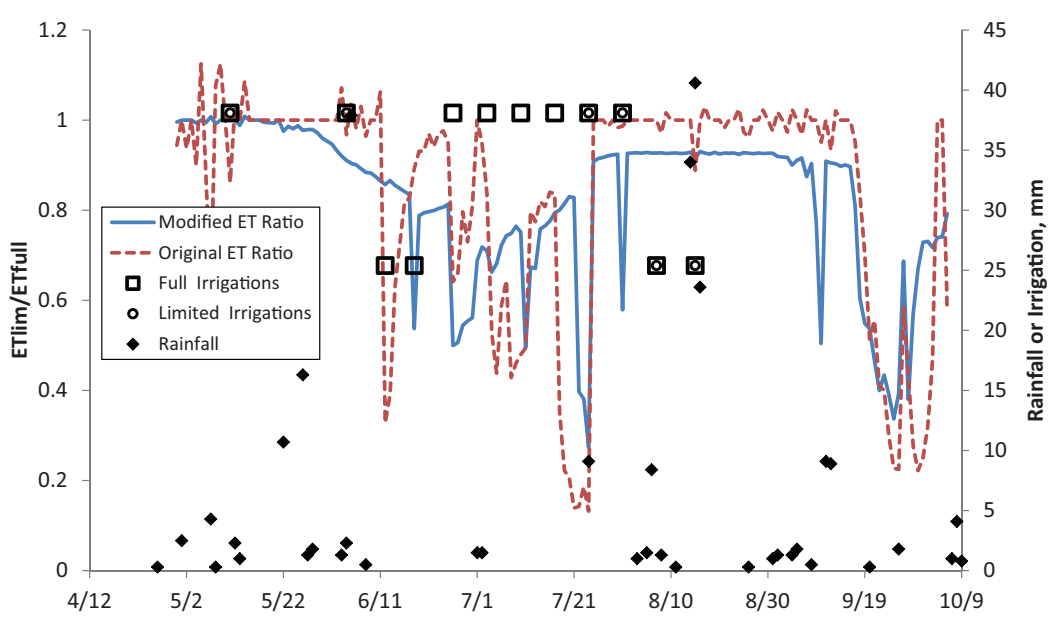

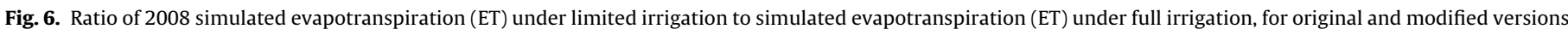
of model (left axis). Points mark individual irrigation and rainfall events (right axis).

Table 5

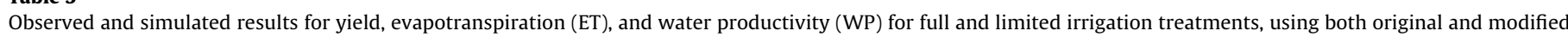
versions of the model.

\begin{tabular}{|c|c|c|c|c|c|c|c|c|c|c|}
\hline \multirow[t]{2}{*}{ Treatment } & \multirow[t]{2}{*}{ Year } & \multicolumn{3}{|c|}{ Yield (kg ha $\left.{ }^{-1}\right)$} & \multicolumn{3}{|c|}{ Cumulative ET (mm) } & \multicolumn{3}{|c|}{ WP $\left(\mathrm{kg} \mathrm{ha}^{-1} \mathrm{~mm}^{-1}\right)$} \\
\hline & & Observed & $\begin{array}{l}\text { Original } \\
\text { simulated }\end{array}$ & $\begin{array}{l}\text { Modified } \\
\text { simulated }\end{array}$ & Observed & $\begin{array}{l}\text { Original } \\
\text { simulated }\end{array}$ & $\begin{array}{l}\text { Modified } \\
\text { simulated }\end{array}$ & Observed & $\begin{array}{l}\text { Original } \\
\text { simulated }\end{array}$ & $\begin{array}{l}\text { Modified } \\
\text { simulated }\end{array}$ \\
\hline \multirow[t]{6}{*}{ Full } & 2006 & 11,107 & 11,373 & 11,373 & 553 & 561 & 556 & 20.1 & 20.3 & 20.5 \\
\hline & 2007 & 11,670 & 9810 & 9810 & 556 & 587 & 526 & 21.0 & 16.7 & 18.7 \\
\hline & 2008 & 10,863 & 12,733 & 12,727 & 650 & 679 & 608 & 16.7 & 18.8 & 20.9 \\
\hline & 2009 & 10,755 & 8659 & 8659 & 527 & 596 & 512 & 20.4 & 14.5 & 16.9 \\
\hline & 2010 & 12,307 & 12,724 & 12,723 & 651 & 621 & 582 & 18.9 & 20.5 & 21.9 \\
\hline & Mean & 11,340 & 11,060 & 11,058 & 587 & 609 & 557 & 19.4 & 18.2 & 19.8 \\
\hline \multirow[t]{6}{*}{ Limited } & 2006 & 8916 & 7851 & 9723 & 345 & 402 & 395 & 25.8 & 19.5 & 24.6 \\
\hline & 2007 & 8484 & 7378 & 9436 & 386 & 491 & 454 & 22.0 & 15.0 & 20.8 \\
\hline & 2008 & 10,451 & 9611 & 11,628 & 454 & 539 & 518 & 23.0 & 17.8 & 22.4 \\
\hline & 2009 & 8301 & 6577 & 6136 & 481 & 549 & 455 & 17.3 & 12.0 & 13.5 \\
\hline & 2010 & 10,129 & 8896 & 8426 & 441 & 522 & 465 & 23.0 & 17.0 & 18.1 \\
\hline & Mean & 9256 & 8063 & 9070 & 421 & 501 & 457 & 22.2 & 16.3 & 19.9 \\
\hline
\end{tabular}

were compared against original model values (Table 5), and statistical comparisons of both model versions were performed against observed data (Table 6). Late planting and cool seasonal weather caused the model, which advances growth stages and accumulates grain biomass based on thermal time, to predict considerably low yields in 2009 (efforts were made to alter default temperature parameters governing grain growth, but no significant changes were obtained).

Simulated yield changed little with modifications to the model under full irrigation, with the mean simulated yield over the five years differing by only $2 \mathrm{~kg} \mathrm{ha}^{-1}$ (Table 5), leading to very little statistical difference between the models (Table 6). Simulated yields under limited irrigation generally increased with the dynamic $K_{C D}$ change, with mean yield increasing by $1007 \mathrm{~kg} \mathrm{ha}^{-1}$. Statistically, yield under limited irrigation had a slightly higher RMSD under the new model as compared with the original model. However, RE improved from -12.9 to $-2.0 \%$. Both the original and modified CERES-Maize models simulated higher limited irrigation yields in 2006-2008 while simulating slightly lower yields in 2009-2010.

There were significant improvements in ET estimation for the limited irrigation treatment, as mean simulated ET was lowered from 501 to $457 \mathrm{~mm}$. This was still higher than the observed ET (421 mm) but much improved statistically (RMSD of $80.9 \mathrm{~mm}$ for the original model and $49.9 \mathrm{~mm}$ for the modified model). Furthermore, RE was reduced from $18.8 \%$ to $8.5 \%$. Simulated ET under full irrigation was slightly overestimated for the original model (mean

Table 6

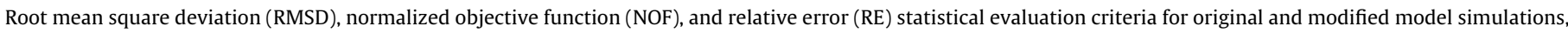
both irrigation treatments, and outputs of yield, evapotranspiration (ET), and water productivity (WP).

\begin{tabular}{|c|c|c|c|c|c|c|c|}
\hline \multirow[t]{2}{*}{ Evaluation criteria } & \multirow[t]{2}{*}{ Treatment } & \multicolumn{2}{|c|}{ Yield $\left(\mathrm{kg} \mathrm{ha}^{-1}\right)$} & \multicolumn{2}{|c|}{ Cumulative ET (mm) } & \multicolumn{2}{|c|}{$\mathrm{WP}\left(\mathrm{kg} \mathrm{ha}^{-1} \mathrm{~mm}^{-1}\right)$} \\
\hline & & $\begin{array}{l}\text { Original } \\
\text { simulated }\end{array}$ & $\begin{array}{l}\text { Modified } \\
\text { simulated }\end{array}$ & $\begin{array}{l}\text { Original } \\
\text { simulated }\end{array}$ & $\begin{array}{l}\text { Modified } \\
\text { simulated }\end{array}$ & $\begin{array}{l}\text { Original } \\
\text { simulated }\end{array}$ & $\begin{array}{l}\text { Modified } \\
\text { simulated }\end{array}$ \\
\hline \multirow[t]{2}{*}{ RMSD (output unit) } & Full & 1523 & 1521 & 38.8 & 39.1 & 3.45 & 2.98 \\
\hline & Limited & 1229 & 1451 & 80.9 & 49.9 & 5.97 & 2.86 \\
\hline \multirow[t]{2}{*}{ NOF (unitless) } & Full & 0.134 & 0.134 & 0.066 & 0.067 & 0.178 & 0.153 \\
\hline & Limited & 0.133 & 0.157 & 0.192 & 0.119 & 0.269 & 0.129 \\
\hline \multirow[t]{2}{*}{$\operatorname{RE}(\%)$} & Full & -2.47 & -2.49 & 3.64 & -5.21 & -6.53 & 1.76 \\
\hline & Limited & -12.90 & -2.01 & 18.79 & 8.54 & -26.70 & -10.46 \\
\hline
\end{tabular}


of $587 \mathrm{~mm}$ observed and 609 simulated, $\mathrm{RE}=3.6 \%$ ), whereas the modified model now slightly underestimates ET (simulated mean of $557 \mathrm{~mm}, \mathrm{RE}=-5.2 \%$ ). This is likely due to the original model estimating high ET during early vegetative periods with low LAI, whereas with the modified model the ET will be reduced. Statistically, when including 2009 data, there was little difference in simulated ET under full irrigation (RMSD of $38.8 \mathrm{~mm}$ for the original model and $39.1 \mathrm{~mm}$ for the modified model).

Evett and Tolk (2009) suggest that crop models correctly simulate WP under well-watered conditions, but tend to poorly predict WP under conditions of water stress. As resolution of this issue is a main goal of this study, it is interesting to note the differences in WP averaged among the years (Table 6 ). Experimental observations indicated that WP under limited irrigation $\left(22.2 \mathrm{~kg} \mathrm{ha}^{-1} \mathrm{~mm}^{-1}\right)$ was higher than under full irrigation $\left(19.4 \mathrm{~kg} \mathrm{ha}^{-1} \mathrm{~mm}^{-1}\right)$. Using the modified model to predict WP under full irrigation, simulated WP value was very close to observed $\left(19.8 \mathrm{~kg} \mathrm{ha}^{-1} \mathrm{~mm}^{-1}\right)$. However, despite statistically improved simulation of WP under limited irrigation, the modified model failed to duplicate the observed increase in WP for this treatment, with simulated WP of $19.9 \mathrm{~kg} \mathrm{ha}^{-1} \mathrm{~mm}^{-1}$ being nearly the same as under full irrigation. This was due to a combination of under-predicted yield and overpredicted cumulative ET for the limited irrigation treatment. Many studies indicate potential for higher WP under limited or deficit irrigation, for example Ge et al. (2012) found that while severe water stress can cause significant reductions in maize WP, more minimal levels of water stress can increase WP. If increased WP is physiologically possible under limited irrigation management as observations from this and other studies suggest, future efforts should be made to further improve both yield and ET simulation under limited irrigation conditions with relevant crop models.

When including 2009 data, prediction of WP was slightly improved for full irrigation (RMSD decreased from 3.45 to $2.98 \mathrm{~kg} \mathrm{ha}^{-1} \mathrm{~mm}^{-1}$, RE changed from -6.5 to $1.8 \%$ ) and significantly improved for limited irrigation (RMSD decreased from 5.97 to $2.86 \mathrm{~kg} \mathrm{ha}^{-1} \mathrm{~mm}^{-1}$, RE changed from $-26.7 \%$ to $-10.5 \%$ ). Both irrigation treatments had similar RMSD values under the modified model, an overall improvement over the original model where the RMSD was much higher for limited irrigation than for full irrigation.

The NOF statistic is convenient because it divides the RMSD by the observed mean, thus normalizing the value so it can be directly compared between model output responses, treatments, and CERES-Maize model versions. Under full irrigation, NOF statistics indicate ET was the best simulated output response $(0.066$ and 0.067 for respective original and modified model versions), followed by yield ( 0.134 for both model versions) and WP where the modified simulation improved NOF from 0.178 to 0.153 . NOF statistics indicated more mixed results for the limited irrigation treatment: the original model performance was best with yield ( 0.133$)$ followed by ET ( 0.192$)$ and WP ( 0.269$)$; the modified model performed best with ET (0.119), followed by WP (0.129) and yield (0.157).

\subsection{Synthetic water production functions}

The new dynamic $K_{C D}$ function was applied to the two observed irrigation treatments, as well as three new hypothetical irrigation scenarios as described in Table 4, and yield was shown as a function of ET (Fig. 7). As discussed previously, CERES-Maize simulations poorly matched 2009 observed data for both treatments because of abnormally cold weather conditions. The 2009 data was therefore omitted from this analysis. Full irrigation, as expected, exhibited both high yield and high ET, whereas limited irrigation exhibited lower values for both yield and ET. The Full, Full Anthesis Only, Stress Anthesis Only, and 50\% Full treatments (all treatments but Limited) appear to form the following lin-

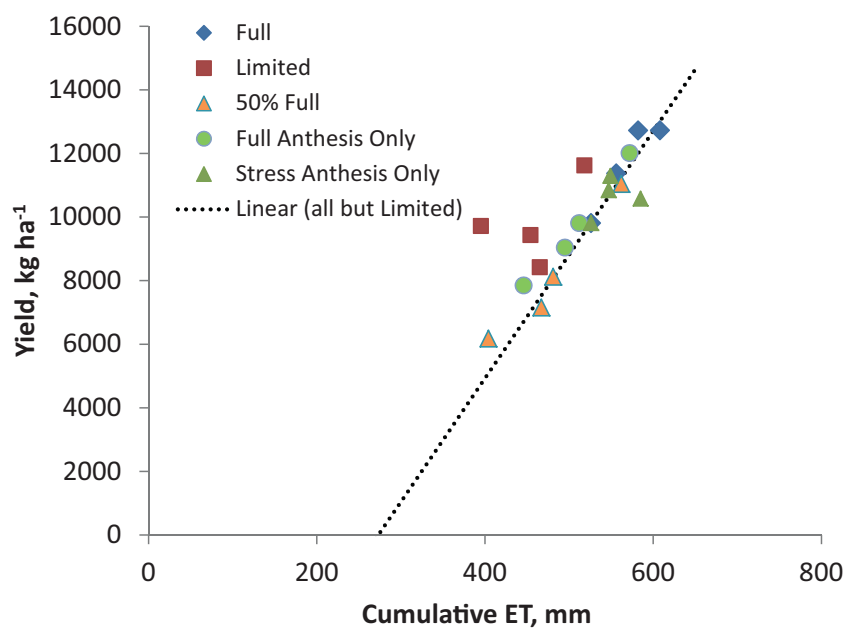

Fig. 7. Model-predicted water production function (WPF) simulations based on two observed irrigation management treatments and three hypothetical treatments, as described in Table 4.

ear relationship: Yield $\mathrm{kg} \mathrm{ha}^{-1}=38.85 \times\left(\mathrm{ET}_{\mathrm{mm}}-273\right), R^{2}=0.901$. However, the Limited treatment shown in Fig. 7 is distinctly different from the above linear relationship in three out of four years, indicating that the modified model predicts higher yield for given values of ET when stress occurs at the vegetative growth stage only. This relationship is similar in shape to the experimental water production functions for maize in Turkey found by Çakir (2004), but has a steeper slope $\left(38.85 \mathrm{~kg} \mathrm{ha}^{-1} \mathrm{~mm}^{-1}\right.$ ET in the model, as compared with observed slopes of $21.33,18.09$, and $14.48 \mathrm{~kg} \mathrm{ha}^{-1} \mathrm{~mm}^{-1}$ ET found by Çakir in three consecutive years). It is likely that water production functions such as these are site-specific and would change with climate, soils, maize variety, etc.

Individual values for yield and cumulative ET were plotted for each "synthetic" limited irrigation treatment (Fig. 8), along with the best fit line from Fig. 7 that represents the linear WPF assumed for other types of management. On average, the plot of the $20 \mathrm{~mm}$ treatment (which essentially represents a full irrigation simulation because there is minimal resultant stress) lands very near the line of the WPF. However, under this limited irrigation management

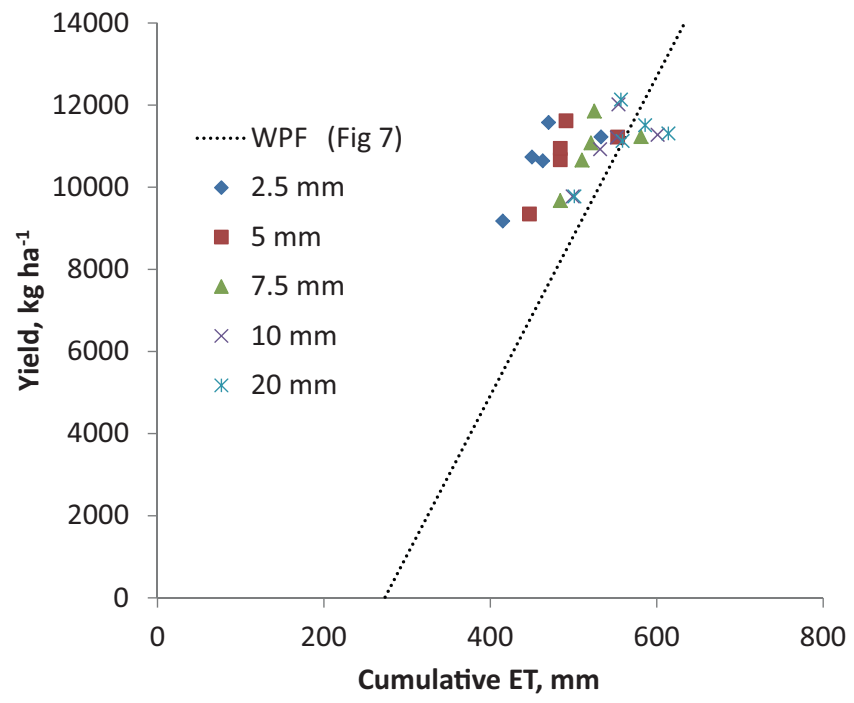

Fig. 8. Water production function (WPF) simulations using hypothetical limited irrigation treatments. Dotted line taken from WPF line defined by Fig. 7. Treatment name in legend indicates weekly irrigation amount during the vegetative stage $(\mathrm{mm})$. No water stress occurred during the reproductive stage for any treatment. 


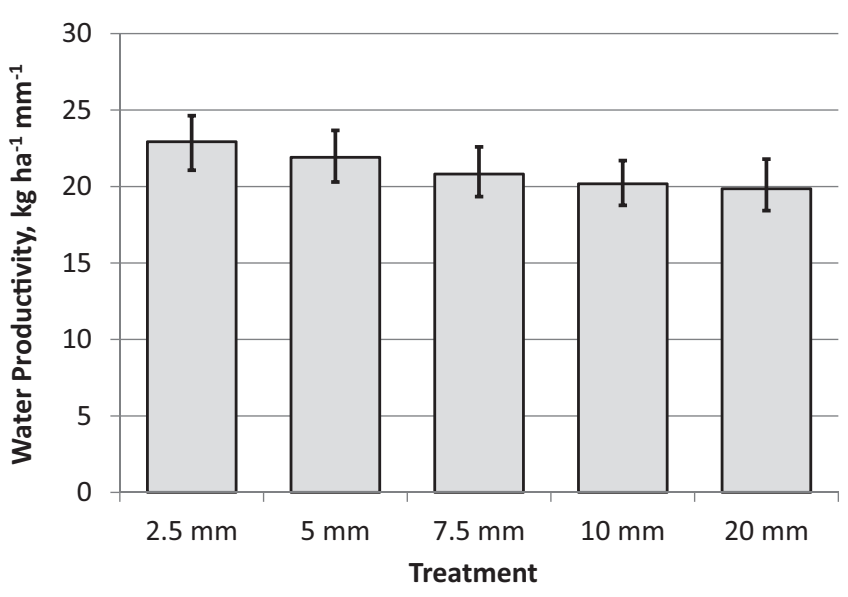

Fig. 9. Mean simulated water productivity $(\mathrm{WP}=$ yield/ET) for varying synthetic treatments, indicating weekly water input during the vegetative growth stage. Error bars indicate minimum and maximum values from the five years simulated.

strategy the CERES-Maize model predicts that significant savings in ET can occur with minimal losses to yield. As each treatment applies less water there is a slight drop in yield; however, ET is reduced relatively more, creating points that are above the linear water production function curve. The potential for separate ET-yield relationships can be visualized for the individual irrigation treatments (except for the 2005 year that had higher ET than the others). As less irrigation is applied to the vegetative growth stage, the potential ET-yield relationships appear to shift more to the left (i.e., there is less ET while retaining high yields). WP (Fig. 9) is also shown, indicating that treatments with less water applied during the vegetative stage have a higher WP as well. Further use of the CERES-Maize model in comparison with limited irrigation experiments is needed to verify these relationships, with rain-out shelters or greenhouse experiments suggested to maintain control of the water balance by preventing natural rainfall.

\section{Conclusions}

As previous efforts to use the CERES-Maize crop model ET under water stress have provided less than satisfactory results (e.g., DeJonge et al., 2011), this study evaluated and improved ET simulation under water stress while not negatively impacting other model processes. Local sensitivity results from this study showed that under full irrigation, increasing $K_{c \max }$ could increase predicted cumulative ET, but under limited irrigation increasing $K_{c \max }$ led to significantly decreased predicted yield and vegetative growth with no change in ET. We recommend changing the default value of KEP from 0.685 to 0.5 , as also suggested by López-Cedrón et al. (2008) and Sau et al. (2004). Both of these studies suggest that accurate simulation of output responses (namely yield and ET) becomes an increasing complicated endeavor when water stress is introduced, and CERES-Maize water balance components may need adjustments to become more robust.

While previous methods for evaluating ET using a static crop coefficient (i.e., $K_{C S}$ ) have worked well for studies under non-stressed water conditions, few studies have emphasized ET accumulation under water stress. Because a stressed crop will usually have a smaller leaf area than a non-stressed crop, the ET demand and subsequent actual ET will often be less. Therefore, our new equation that calculates a dynamic crop coefficient $\left(K_{C D}\right)$ as a function of LAI results in a crop coefficient relationship that very closely correlates to that suggested by FAO-56 (Allen, 1998 ) under full irrigation. The new dynamic $K_{C D}$ model modification vastly improved ET estimation under limited irrigation, thereby significantly reducing WP error under limited irrigation (and full irrigation as well). New "synthetic" simulations indicate that the modified CERES-Maize crop model predicts that higher WP of corn can be obtained through limited irrigation management where the crop is water stressed during the vegetative growth stage, and where there is no stress during or following anthesis. The results further suggest that development of new hybrids with higher potential water productivity should consider separately the effects of water stress during vegetative and reproductive growth stages. As knowledge about water stress improves, especially in terms of plant physiologic responses, the dynamic $K_{C D}$ and KEP modifications should be incorporated into new versions of DSSAT models.

While not an easy proposition, the ability of CERES-Maize and other DSSAT models to further improve crop response prediction to limited water, especially in regard to ET, could be again strengthened by working toward more physically and physiologically based model processes. Such model enhancements could be based on stomatal conductance and other parameters that are inputs to physically based ET models. Increased multidisciplinary collaboration between model programmers, field experimentalists, and plant physiologists will be necessary to carry out such an endeavor. It is likely that increases in WP as described herein may not be attainable in every year under limited irrigation management, as there is inherent variability and randomness in precipitation and other weather patterns that will ultimately dictate final yield and ET. For example, in a season with a wet spring and little potential to apply water stress during the vegetative stage, there may not be the opportunity to reduce ET during the early growth stages. It may be desirable to compare a more controlled physiological experiment to CERES-Maize using a rainout shelter and/or greenhouse tests.

\section{References}

Ahuja, L.R., Ma, L., Timlin, D.J., 2006. Trans-disciplinary soil physics research critical to synthesis and modeling of agricultural systems. Soil Science Society of America Journal 70, 311-326.

Al-Kaisi, M., Brun, L.J., Enz, J.W., 1989. Transpiration and evapotranspiration from maize as related to leaf area index. Agricultural and Forest Meteorology 48(1-2) 111-116.

Allen, R.G., Periera, L.S., Raes, D., Smith, M., 1998. Crop Evapotranspiration: Guidelines for Computing Crop Water Requirements. FAO Irrigation and Drainage Paper 56. Food and Agriculture Organization of the United Nations, Rome.

Anderson-Wilk, M., 2008. Rising expectations for conservation in water-scarce times. Journal of Soil and Water Conservation 63, 4A.

Barrett, J.H., Skogerboe, G.V., 1978. Effects of irrigation regime on maize yields. Journal of the Irrigation and Drainage Division - ASCE 104, 179-194.

Çakir, R., 2004. Effect of water stress at different development stages on vegetative and reproductive growth of corn. Field Crops Research 89 (1), 1-16.

DeJonge, K.C., Ascough, J.C., Ahmadi, M., Andales, A.A., Arabi, M., 2012. Global sensitivity and uncertainty analysis of a dynamic agroecosystem model under different irrigation treatments. Ecological Modelling 231, 113-125.

DeJonge, K.C., Andales, A.A., Ascough, J.C., Hansen, N., 2011. Modeling of full and limited irrigation scenarios for corn in a semiarid environment. Transactions of the ASABE 54, 481-492.

Doorenbos, J., Kassam, A.K., 1979. Yield Response to Water Irrigation and Drainage Paper 33. FAO, United Nations, Rome.

Duchemin, B., Hadria, R., Erraki, S., Boulet, G., Maisongrande, P., Chehbouni, A Escadafal, R., Essahar, J., Hoedjes, J.C.B., Kharrou, M.H., Khabba, S., Mougenot, B. Olioso, A., Rodriguez, J.-C., Simonneaux, V., 2006. Monitoring wheat phenology and irrigation in Central Morocco: on the use of relationships between evapotranspiration, crops coefficients, leaf area index and remotely sensed vegetation indices. Agricultural Water Management 79, 1-27.

English, M.J., Solomon, K.H., Hoffman, G.J., 2002. A paradigm shift in irrigation management. Journal of the Irrigation and Drainage Division - ASCE 128, 267-277.

Evett, S.R., Tolk, J.A., 2009. Introduction: can water use efficiency be modeled well enough to impact crop management? Agronomy Journal 101 (3), 423-425.

Farre, I., Faci, J.M., 2009. Deficit irrigation in maize for reducing agricultural water use in a Mediterranean environment. Agricultural Water Management 96, 383-394.

Ge, T., Sui, F., Bai, L., Tong, C., Sun, N., 2012. Effects of water stress on growth, biomass partitioning, and water-use efficiency in summer maize (Zea mays L.) throughout the growth cycle. Acta Physiologiae Plantarum 34 (3), 1043-1053.

Gilley, J.R., Watts, D.G., Sullivan, C.Y., 1980. Management of Irrigation Agriculture with a Limited Water and Energy Supply. Institute of Agr. and Natural Res. University of Nebraska-Lincoln, Lincoln, Nebraska, p. 168. 
Hoogenboom, G., Jones, J.W., Wilkens, P.W., Porter, C.H., Boote, K.J., Hunt, L.A., Singh, U., Lizaso, J.L., White, J.W., Uryasev, O., Royce, F.S., Ogoshi, R., Gijsman, A.J., Tsuji, G.Y., 2010. Decision Support System for Agrotechnology Transfer (DSSAT). University of Hawaii, Honolulu, HI, USA.

ICASA (International Consortium for Agricultural Systems Applications), 2008. Simulating Water Limited Production (presentation). 2008 Training Program on DSSAT, The University of Georgia.

Igbadun, H.E., Salim, B.A., Tarimo, A., Mahoo, H.F., 2008. Effects of deficit irrigation scheduling on yields and soil water balance of irrigated maize. Irrigation Science $27,11-23$.

Jones, C.A., Kiniry, J.R., 1986. CERES-Maize: A Simulation Model of Maize Growth and Development Texas. A\&M University Press, College Station, TX, USA.

Jones, J.W., Hoogenboom, G., Porter, C.H., Boote, K.J., Batchelor, W.D., Hunt, L.A., Wilkens, P.W., Singh, U., Gijsman, A.J., Ritchie, J.T., 2003. The DSSAT cropping system model. European Journal of Agronomy 18, 235-265.

Kang, S.Z., Gu, B.J., Du, T.S., Zhang, J.H., 2003. Crop coefficient and ratio of transpiration to evapotranspiration of winter wheat and maize in a semi-humid region. Agricultural Water Management 59, 239-254.

Klocke, N.L., Payero, J.O., Schneekloth, J.P., 2007. Long-term response of corn to limited irrigation and crop rotations. Transactions of the ASABE 50, 2117-2124.

Klocke, N.L., Schneekloth, J.P., Melvin, S.R., Clark, R.T., Payero, J.O., 2004. Field scale limited irrigation scenarios for water policy strategies. Applied Engineering in Agriculture 20, 623-631.

Ko, J., Piccinni, G., 2009. Corn yield responses under crop evapotranspiration-based irrigation management. Agricultural Water Management 96, 799-808.

López-Cedrón, F.X., Boote, K.J., Pineiro, J., Sau, F., 2008. Improving the CERES-Maize model ability to simulate water deficit impact on maize production and yield components. Agronomy Journal 100 (2), 296-307.

Ma, L., Nielsen, D.C., Ahuja, L.R., Kiniry, J.R., Hanson, J.D., Hoogenboom, G., 2002. An evaluation of RZWQM, CROPGRO, and CERES-Maize for responses to water stress in the central Great Plains of the U.S. In: Ahuja, L.R., et al. (Eds.), Agricultural System Models in Field Research and Technology Transfer. Lewis Publishers, Boca Raton, FL, USA, pp. 119-148.

Mansouri-Far, C., Sanavy, S., Saberali, S.F., 2010. Maize yield response to deficit irrigation during low-sensitive growth stages and nitrogen rate under semi-arid climatic conditions. Agricultural Water Management 97, 12-22.

Mastrorilli, M., Katerji, N., Nouna, B.B., 2003. Using the CERES-Maize model in a semiarid Mediterranean environment. Validation of three revised versions. European Journal of Agronomy 19, 125-134.

Nouna, B.B., Katerji, N., Mastrorilli, M., 2000. Using the CERES-Maize model in a semiarid Mediterranean environment. Evaluation of model performance. European Journal of Agronomy 13, 309-322.
Payero, J.O., Melvin, S.R., Irmak, S., Tarkalson, D., 2006. Yield response of corn to deficit irrigation in a semiarid climate. Agricultural Water Management 84, $101-112$.

Payero, J.O., Tarkalson, D.D., Irmak, S., Davison, D., Petersen, J.L., 2009. Effect of timing of a deficit-irrigation allocation on corn evapotranspiration, yield, water use efficiency and dry mass. Agricultural Water Management 96, 1387-1397.

Priestley, C.H.B., Taylor, R.J., 1972. On the assessment of surface heat flux and evaporation using large-scale parameters. Monthly Weather Review 100, 81-92.

Ritchie, J.T., 1985. A user-oriented model of the soil water balance in wheat. In: Fry, E., Atkin, T.K. (Eds.), Wheat Growth and Modeling. Plenum Press, New York, NY, pp. 293-305.

Ritchie, J.T., 1998. Soil water balance and plant water stress. In: Tsuji, G.Y., et al. (Eds.), Understanding Options for Agricultural Production. Kluwer Academic Publishing, Dordrecht, The Netherlands, pp. 41-54.

Ritchie, J.T., Singh, U., Godwin, D.C., Bowen, W.T., 1998. Cereal growth, development and yield. In: Tsuji, G.Y., et al. (Eds.), Understanding Options for Agricultural Production. Kluwer Academic Publishing, Dordrecht, The Netherlands, pp. 79-98.

Saseendran, S.A., Ahuja, L.R., Nielsen, D.C., Trout, T.J., Ma, L., 2008a. Use of crop simulation models to evaluate limited irrigation management options for corn in a semiarid environment. Water Resources Research, 44.

Saseendran, S.A., Ahuja, L.R., Ma, L., Timlin, D.J., Stockle, C.O., Boote, K.J., Hoogenboom, G., 2008b. Current water deficit stress simulations in selected agricultural system simulation models. In: Ahuja, L.R., et al. (Eds.), Response of Crops to Limited Water: Understanding and Modeling Water Stress Effects on Plant Growth Processes. Am. Society Agron., Crop Sci. Soc. Am., Soil Sci. Soc. Am., Madison, WI, USA, pp. 1-38.

Sau, F., Boote, K.J., Bostick, W.M., Jones, J.W., Minguez, M.I., 2004. Testing and improving evapotranspiration and soil water balance of the DSSAT crop models. Agronomy Journal 96, 1243-1257.

Schneekloth, J.P., Bauder, T.A., Hansen, N., 2009. Limited Irrigation Management: Principles and Practices. Colorado State University Extension. Fact Sheet No. 4 Fort Collins, Colorado, p. 720.

SCS, 1972. Hydrology Section 4, Soil Conservation Service, National Engineering Handbook. GPO, Washington, D.C., USA.

Smith, D.H., Klein, K., Bartholomay, R., Broner, I., Cardon, G.E., Frasier, W.M., Kuharich, R., Lile, D.C., Gross, M., Parker, D., Simpson, H., Wilkinson, E., 1996. Irrigation Water Conservation: Opportunities and Limitations in Colorado - A Report of the Agricultural Water Conservation Task Force. Colorado Water Resources Research Institute, Colorado State University, Fort Collins, CO.

Xie, Y., Kiniry, J.R., Nedbalek, V., Rosenthal, W.D., 2001. Maize and sorghum simulations with CERES-Maize SORKAM, and ALMANAC under water-limiting conditions. Agronomy Journal 93, 1148-1155. 